\title{
Evaluating the effects of faculty development: theoretical framework and empirical implementation
}

This is an Accepted Manuscript of an article published by Taylor \& Francis in International Journal for Academic Development on September 19th 2019 , available online:

http://www.tandfonline.com/10.1080/1360144X.2019.1659798.

\section{Bernadette Charlier*, Marie Lambert*}

bernadette.charlier@unifr.ch, marie.lambert@unifr.ch

* Centre for Faculty Development, University of Fribourg, Switzerland

\begin{abstract}
This article implements a systemic evaluation framework to evaluate the long-term effects of a specific program characterized by a SoTL approach and a hybrid learning environment. The importance of the difference between the perception of long-term effects on individual professional development and the development of collective practices is interpreted by certain shortcomings of the FD program's learning design and its non-alignment with institutional practices. Based on this in-depth research, concrete ways to take into account the complexity of FD programs are proposed for both research and development of FD programs and their impact at an individual and institutional level.
\end{abstract}

KEYWORDS: Scholarship of Teaching and Learning, hybrid learning environment, learning design, evaluation 


\section{Introduction}

Although the complexity of Faculty Development processes has been acknowledged in the adoption of systemic evaluation frameworks (Chalmers \& Gardiner, 2015), several gaps still need to be filled to enable faculty developers to carry out evaluations taking this complexity into account and to contribute to building an empirical knowledge base (Phuong, Cole \& Zarestky, 2018), enabling them to orient their actions and evaluate their effects both at an individual and institutional level. (1) The lists of process indicators "which reveal how programmes are delivered within the particular context" (Chalmers \& Gardiner, 2015, p. 86), although theoretically and empirically based, do not allow for the description of the "system of methods" (Reigeluth \& Carr-Chellman, 2009, p. 63) or learning design (Boud \& Prosser, 2002) of the FD programs evaluated. That is to say "the systems of methods that are frequently used together in high quality instruction, and (...) the situations in which they work so well together" (Reigeluth \& Carr-Chellman, 2009, p. 63). (2) The evaluation seldom takes into account the fact that, depending on their characteristics, participants have different perceptions of the learning environments and contexts in which they operate (Boud \& Prosser, 2002; Entwistle, 2018). (3) Faculty developers seldom use validated evaluation tools to evaluate their action and guide it, particularly when it comes to long-term effects on the working environment and pedagogical teams (Kolomitro \& Anstey, 2017).

With Bamber and Stefani (2016), we acknowledge that "situated local knowledge of our activities is a vital component of evidencing" (p. 252). Furthermore, we demonstrate that this knowledge can be described in a way that makes our assessments of FD learning design comparable. Based on our own research (Deschryver \& Charlier, 2014), we will present an instrument to describe, recognize and situate the learning design adopted in formal FD programs offering a hybrid learning environment. Here, the choice of the label "hybrid" instead of "blended" "refers to the creation of a new entity whose major characteristics are 
the presence-distance articulation and the integration of technologies to support the teaching-learning process environments" (Charlier, Deschryver, \& Peraya, 2006). Congruently, based on a review of the literature, we will propose criteria to identify the type of SoTL learning design adopted. Furthermore, acknowledging with Jones, Lygo-Baker, Markless, Rienties, and Di Napoli (2017) "the difficulty of attributing simple cause and effect to complex environment" (p. 116), we will apply our systemic evaluation framework through a mixed method research design and show its value for research and the improvement of our FD practices.

\section{Theoretical framework}

Our systemic evaluation framework (Fig. 1) adapts (Charlier, Cosnefroy, Jézégou, \& Lameul, 2015) the model provided by Entwistle (2018) that shows how individual student characteristics interact with those of the learning environment to explain the inter-individual differences in learning and understanding through the mediation of interactions between participants and the environment.

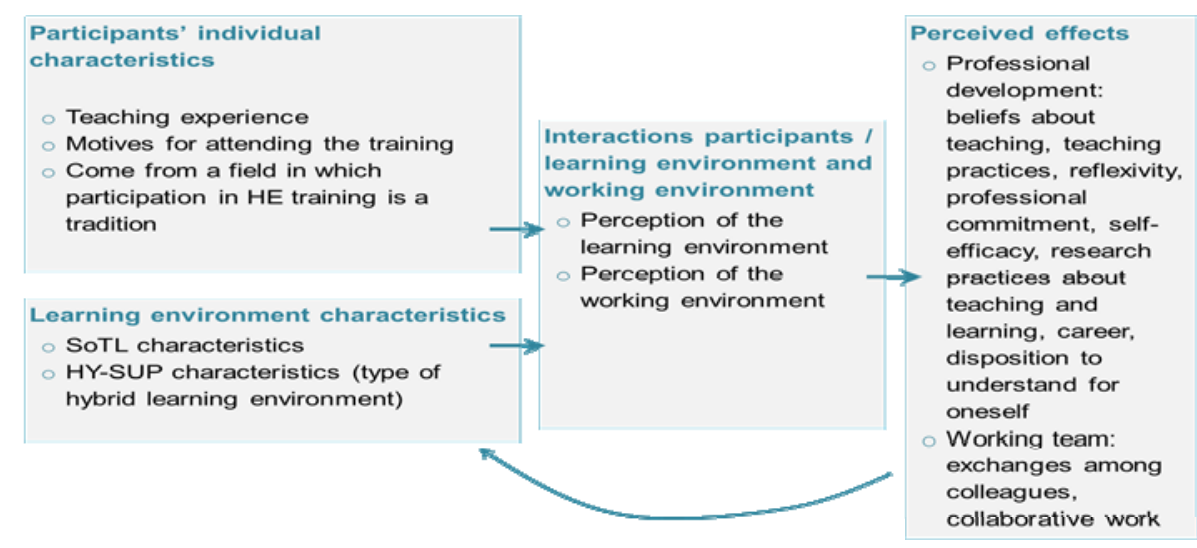

Fig. 1. Systemic framework for the evaluation of an FD program 
Below we develop the descriptors for a hybrid learning environment and the learning designs of SoTL FD programs. The other variables are further described in the methodological part.

\section{A hybrid learning environment}

The European research HY-SUP (Deschryver \& Charlier, 2014) has made it possible, based on a theoretical framework (Charlier, Deschryver \& Peraya, 2006), to define and describe the learning design of a hybrid learning environment. A mixed methods research design (174 questionnaires on the learning environment and 77 interviews with HE professors), based on factorial and cluster analyses, enabled the identification of 14 descriptive factors distributed according to 5 dimensions: the articulation of face-to-face and distance activities, the forms of mediatisation and the forms of mediation, the forms of human accompaniment, and the openness of the learning environment. On this basis, a typology describing six types of learning designs in a hybrid learning environment has been produced. Each type has been illustrated through qualitative descriptions and metaphors. This research also highlighted positive relationships between these types and the quality of learning as perceived by students and teachers. In addition, the research has produced an instrument (a self-positioning tool, 14 items, 4 points Likert scale) that can easily be used by teachers to describe their learning environment. The six types developed by the project are:

"The scene (Type 1)-content-oriented "teaching" configuration, characterized by support to courses and the availability of mainly textual resources

The screen (Type 2) - content-oriented "teaching" configuration, characterized by support to on-site courses and the availability of numerous multimedia resources The cockpit (Type 3) - "teaching" configuration oriented to the organization of courses eased by the use of management tools and sometimes tending towards the integration of interpersonal and reflexive targets 
The crew (Type 4) - "learning" configuration focused on supporting the process of knowledge building and on interpersonal interactions

The metro (Type 5) - "learning" configuration focused on various forms of support and tending towards openness.

The ecosystem (Type 6) - "learning" configuration characterized by the exploiting of a large number of technological and educational opportunities offered by hybrid systems" (HY-SUP website).

\section{The Scholarship of Teaching and Learning environment}

Going back to the origins of the concept, it must be noted that the "scholarship of teaching" mentioned by Boyer (1990) had no theoretical or empirical basis. Indeed, the idea originated in a report written by the author, then president of the Carnegie Foundation for the Advancement of Teaching. That report was a protest aimed primarily at denouncing certain dysfunctions in higher education in the United States and demanding changes. With reference to our evaluation framework (Fig. 1), two main issues can be identified. (1) The lack of a framework distinguishing between the learning designs of FD programs adopting a SoTL approach. When indicators are proposed, they sometimes concern the learning effect, that is to say the adoption of what Tight (2018) calls a "'researcherly' attitude towards teaching and learning practice" (p. 63) and more rarely the methods used (Chalmers \& Gardiner, 2015). (2) Empirical research, often based on case analysis, does not allow the observed effects to be interpreted in relation to the individual characteristics of the participants, their representations of the FD programs and their learning designs (Fig. 1). A possible research project, as we did for hybrid learning environments, would be to characterize the learning designs that claim to follow a SoTL approach, make their descriptions comparable and evaluate their effects. As a starting point, based on the literature, we suggest a set of components that, when articulated, make it possible to characterize and distinguish between learning designs of FD programs 
claiming to adopt a SoTL approach. We divide the dimensions described in the literature into two main categories characterizing the instructional learning designs, what Reigeluth and Carr-Chellman (2009) call "systems of methods": the intended learning outcomes and the approaches to instruction.

\section{Learning outcomes}

A possible aim of an FD program could be the adoption of a SoTL approach. Such an approach, according to the literature (Bélanger, 2010; Brew, 2011; Daele, Biémar, Malengrez, \& Oger, 2014; Rege-Colet, McAlpine, Fanghanel, \& Weston, 2011) could correspond to the following criteria:

- A critical inquiry into teaching and learning, that enables the description and analysis of pedagogical practices,

- not only to improve the individual education and learning of students, but also - to some extent - the advancement of the teaching profession and the improvement of the quality of the teaching profession as well as teaching and learning at an institution level.

If the program adopts a more restricted perspective (Chick, 2015; Bélanger 2010; Daele et al., 2014; Rege-Colet et al., 2011), we would need the following additional criteria: a rigorous, systemic research approach complying with the norms of scientific research, the results of which are made public.

Several authors (Bélanger, 2010; Huet, 2012; Tight, 2018) link the SoTL approach to the professional or academic development with a commitment to SoTL supporting that development. At an institutional level, SoTL could also contribute to improving the quality of teaching and learning according to some authors (Webb, 2015; Larsson, Anderberg, \& Olsson, 2015). In this direction, Mårtensson, Roxå and Olsson (2011) analyse the case of an 
FD program aimed at the development of a quality culture in teaching and learning at an institutional level.

Approaches to instruction

According to Reigeluth and Carr-Chellman (2009), instructional approaches are primarily "management and classroom attitude approaches rather than specific method of teaching and learning" (p. 64). Chalmers and Gardiner (2015) talk about process indicators for a SoTL approach that are: “(1) encourage critical reflection of participants' beliefs and practices regarding teaching, learning and assessment and (2) incorporate research which informs teaching and learning in higher education" (p. 87). Focusing of the production of artefacts such as teaching portfolios or research papers, Larsson et al. (2015) provide a precise framework to describe "how the pedagogical practice is expressed in teaching portfolios" (p. 124). It should be noted that Chalmers and Gardiner (2015) in their "Academic Professional Development Effectiveness Frameworks" describe indicators in alignment with indicators relating to inputs, outputs and outcomes of formal FD programs and with indicators describing the institutional level (policy, resourcing, and culture). With these authors, we believe that such descriptors, combined with other descriptors associated with other focuses of FD programs such as "teacher knowledge, skills and practice" (p. 87), if used to conduct empirical research, would allow the recognition of the variety of learning designs in FD programs and enable the development of a common knowledge base. 


\section{Research context}

Organized since the 2003-2004 academic year, the FD in-service program at the University of Fribourg (Switzerland) offers a voluntary opportunity to teachers already engaged in an HE practice either in universities or HE institutions to develop themselves in four domains: teaching practices, assessment methods, and professional and institutional development. Three options are offered in French, German and bilingually: a 15 ECTS Certificate of Advanced Studies (CAS), a 30 ECTS Diploma of Advanced Studies (DAS), and participation on an "à la carte" basis. As the programs are designed from a constructivist perspective in a flexible way and adapted to the experience and learning objectives of each participant, the duration can range from one year to three years. The training consists of four compulsory modules (including participation in a community of practice and intervision) in both the CAS and the DAS. A range of about 20 optional modules to deepen specific themes completes the DAS and "à la carte" offers. To obtain the CAS or DAS, the participants write a final paper (FP) which can take two forms: either a teaching and/or research portfolio including detailed teaching practice analysis, or the description and analysis of a pedagogical project intended to improve their own teaching practice. Since the beginning of the training, more than 300 FPs have been successfully defended.

\section{Research questions and methodology}

\section{Research questions}

The present research includes (1) a descriptive component aimed at situating the FD program according to its learning design and (2) an evaluative component aimed at analysing the differences in participants' perceived learning effects according to their characteristics and their interactions with their learning and working environment. Here are the specific research 
questions we will answer:

- RQ1. What are the individual characteristics of participants?

- RQ2. What are the characteristics of the FD program?

- RQ3. From the point of the view of participants, what are the effects of the FD program on their professional development and on the practices of the team they work in?

- RQ4. What interactions between participants and their working environment lead to what effects?

- RQ5. To what extent do the learning effects perceived by participants correspond to those expected of a SoTL approach?

\section{Methods}

\section{Choice of variables}

The following table, with reference to the conceptual framework (Fig. 1), details the variables selected and their types. 
Table 1. Description of the variables (included in the questionnaire)

\begin{tabular}{|c|c|c|c|c|}
\hline Variable & Role in the model & $\mathrm{Nb}$ & Sample item & Measure \\
\hline $\begin{array}{l}\text { Teaching } \\
\text { experience }\end{array}$ & $\begin{array}{l}\text { Participants' } \\
\text { individual } \\
\text { characteristics }\end{array}$ & 1 & $\begin{array}{l}\text { Years of experience in } \\
\text { higher education }\end{array}$ & $\begin{array}{l}\text { Three categories based on } \\
\text { the number of years: } \\
\text { beginner, advanced, expert. }\end{array}$ \\
\hline $\begin{array}{l}\text { Tradition of } \\
\text { taking part in the } \\
\text { FD program in } \\
\text { the field of work }\end{array}$ & $\begin{array}{l}\text { Participants' } \\
\text { individual } \\
\text { characteristics }\end{array}$ & 1 & Field of work & $\begin{array}{l}\text { Three categories based on } \\
\text { FD program attendance } \\
\text { statistics: weak, medium, } \\
\text { strong. }\end{array}$ \\
\hline $\begin{array}{l}\text { Entry motives } \\
\text { ( } 8 \text { categories })\end{array}$ & $\begin{array}{l}\text { Participants' } \\
\text { individual } \\
\text { characteristics }\end{array}$ & 20 & $\begin{array}{l}\text { I wanted to prepare } \\
\text { myself for new } \\
\text { educational } \\
\text { responsibilities... }\end{array}$ & 5-point Likert scale \\
\hline $\begin{array}{l}\text { SoTL } \\
\text { characteristics }\end{array}$ & $\begin{array}{l}\text { Characteristics of } \\
\text { the learning } \\
\text { environment }\end{array}$ & 4 & $\begin{array}{l}\text { Opportunity to carry out } \\
\text { a critical reflection } \\
\text { about teaching and } \\
\text { learning and to analyse } \\
\text { one's practice }\end{array}$ & $\begin{array}{l}\text { We identified the SoTL } \\
\text { characteristics through a } \\
\text { literature review and used } \\
\text { them to describe the learning } \\
\text { environment. }\end{array}$ \\
\hline $\begin{array}{l}\text { HY-SUP } \\
\text { characteristics }\end{array}$ & $\begin{array}{l}\text { Characteristics of } \\
\text { the learning } \\
\text { environment }\end{array}$ & 14 & $\begin{array}{l}\text { You provide } \\
\text { methodological support } \\
\text { to the participants (e.g. } \\
\text { help with organization } \\
\text { and time management). }\end{array}$ & $\begin{array}{l}\text { We used the HY-SUP self- } \\
\text { evaluation tool to describe } \\
\text { the learning environment } \\
\text { among six different types. }\end{array}$ \\
\hline $\begin{array}{l}\text { Perception of the } \\
\text { learning } \\
\text { environment }\end{array}$ & $\begin{array}{l}\text { Interactions : } \\
\text { participants/learnin } \\
\text { g environment }\end{array}$ & 6 & $\begin{array}{l}\text { Organizational tools are } \\
\text { provided (e.g. } \\
\text { guidelines, calendar). }\end{array}$ & 5-point Likert scale \\
\hline $\begin{array}{l}\text { Perception of the } \\
\text { working } \\
\text { environment }\end{array}$ & $\begin{array}{l}\text { Interactions : } \\
\text { participants/learnin } \\
\text { g environment }\end{array}$ & 13 & $\begin{array}{l}\text { My working } \\
\text { environment allowed } \\
\text { me to carry out varied } \\
\text { and stimulating tasks. }\end{array}$ & 5-point Likert scale \\
\hline $\begin{array}{l}\text { Perceived } \\
\text { individual } \\
\text { learning effects } \\
\text { ( } 8 \text { categories) }\end{array}$ & Perceived effects & 48 & $\begin{array}{l}\text { I changed the planning } \\
\text { of my courses. }\end{array}$ & 5-point Likert scale \\
\hline $\begin{array}{l}\text { Perceived } \\
\text { collective effects }\end{array}$ & Perceived effects & 7 & $\begin{array}{l}\text { We share more about } \\
\text { pedagogical issues } \\
\text { within the working } \\
\text { team. }\end{array}$ & 5-point Likert scale \\
\hline
\end{tabular}


In terms of perceived effects, we distinguish two main categories: those that concern the teacher's professional development (i.e. individual effects) and those that affect the practices of the work team (i.e. collective effects). To evaluate the perceived collective effects, participants were asked to express their perception of their working environment at completion of the FD program. We have adopted the notion of an "enabling" environment developed by Fernagu-Oudet (2012), defined as "an environment that makes resources available to individuals and allows them to use them" (p. 210). To allow individuals to extend their "power to act", Fernagu-Oudet (2012) mentions different aspects to be taken into account, such as the content of the work (e.g. to allow varied and stimulating tasks to be carried out), the ways work is organized (e.g. promoting collaborative work and collective projects), or managing human resources (e.g. providing access to knowledge needed to carry out tasks).

\section{Data collection and data analysis}

We have characterized the FD program in relation to the two descriptive frames of reference presented above: the learning design of the SoTL approach and the hybrid learning environment typology developed by the HY-SUP project. The evaluative component is based on a mixed methods approach (Johnson \& Onwuegbuzie, 2004; Tashakkori \& Teddlie, 2010) combining two sequential studies, one using a questionnaire (study 1) and the other interviews (study 2). Both studies seek to answer the same research questions, but at different levels of detail and depth. Given the sequential approach chosen, the interviews enabled a better understanding of certain questionnaire results, illustrating them, and even qualifying them.

Study 1 (questionnaire) was conducted between November and December 2015 using an electronic questionnaire sent to all those participants who had completed their final paper 
between 2010 and $2015(\mathrm{~N}=96)$. We obtained a response rate of $42 \%(\mathrm{~N}=40)$. The content of the questionnaire is described in Table 1 above.

The sample consists of a majority of women (67\%). The average age is 37 ( $\mathrm{min}=27$, $\max =50)$. On average, respondents report 4 years of experience in higher education when completing their FP $(\min =1, \max =15)$.

The data collected was analysed using various descriptive and inferential statistical methods. Following the results of the descriptive analyses, specific hypotheses were formulated and tested using inferential statistics. For RQ5, correlations between single components of the model were calculated in order to test the mediating effect of the "perception of working environment" variable (See Results). No overall model test was conducted.

Study 2 (interviews) was conducted between March and April 2016 using semi-structured interviews with volunteers who had already completed the questionnaire during the first study $(\mathrm{N}=14)$. The data collected was analysed using a categorical analysis. The interview guide was developed following initial analyses of the questionnaire data.

\section{Results}

\section{RQ1. What are the individual characteristics of participants?}

A first descriptive analysis of the results of the questionnaires shows the importance of several types of entry motives among the 8 categories identified in the literature. Epistemic motives (sample item: "I wanted to acquire new knowledge") and professional ones (sample item: "I wanted to prepare for new educational responsibilities by following adequate training.") figure at the top of the list of the most important motives for engaging in training. Then come the vocational motives (sample item: "I wanted to orient my career towards higher education.") and identity ones (sample item: "I wanted to challenge myself in my role as teacher."). Derived motives (sample item: "I wanted to devote myself to something other than 
my main activity (research, administration, or other).") and socio-affective ones (sample item: "I wanted to meet new people in general (not necessarily related to my professional or educational activities).") appear to be less central for participants. Finally, the motives considered the least important are the economic ones (sample item: "I hoped to obtain a financial advantage thanks to the certification of the training (in the short, medium or long term).") and the prescriptive ones (sample item: "I was required to attend by my supervisor/my employer.").

In order to use the "motives" variable to carry out inferential analyses, we proceeded to an exploratory factor analysis (principal component analysis), which enabled the emergence of three types of more general motives:

- Socio-affective and identity motives;

- Epistemic and professional motives;

- Vocational and economic motives.

Results of further analyses considering these three categories are presented below (See RQ4).

\section{RQ2. What are the characteristics of the FD program?}

In terms of the degree of hybridization, the results of the self-positioning test with respect to the fourteen dimensions of the HY-SUP model designate the learning environment as type 5 (the "metro"). According to the HY-SUP typology, it is therefore a learning environment centred on participants' learning and characterized by openness, freedom of choice and support for learning. This result shows the trainers' perception of the learning environment. The participants' representation acknowledges the characteristics of a type 5: high level of accompaniment (mean=4.12; $\mathrm{SD}=0.21$ ) and openness (mean=4.34; $\mathrm{SD}=0.60$ ). As for the SoTL approach, concerning learning outcomes, trainers considered it as a method to support the professional development of teachers (see individual learning effects) and not as an end in 
itself. At the level of approaches to instruction, the activities correspond to the two descriptors of Chalmers and Gardiner (2015) (see above). Furthermore, the final project (portfolio or project) quality criteria correspond to three of the four criteria described by Larsson et al. (2015): description and analysis of "what is taught, how the subject is taught, effects of teaching on students' learning, linkage and coherence between educational theory and practice" (p. 121). The fourth criterion "sharing/dissemination of expertise and best practices" (p. 121) is not required.

\section{RQ3. From the point of the view of participants, what are the effects of FD program} on their professional development and on the practices of the team they work in?

The descriptive analysis carried out using data obtained from the questionnaires revealed that the effects perceived by the participants in the FD program were numerous and important (Fig. 2).

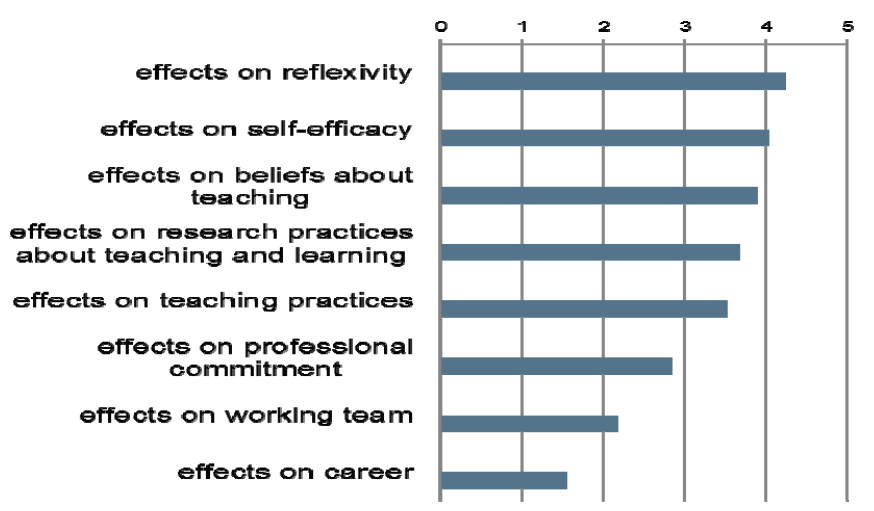

$\begin{array}{cc}\text { Mean } & S D \\ 4.24 & 0.24 \\ 4.03 & 0.11 \\ 3.89 & 0.25 \\ 3.68 & 0.18 \\ 3.51 & 0.26 \\ 2.85 & 0.56 \\ 2.18 & 0.24 \\ 1.55 & 0.19\end{array}$

Fig. 2. Perceived learning effects 
The results of the categorical analysis applied to the interview data are broadly in line with those of the questionnaires. Most categories appear to be important in the interview results and confirm the results of the questionnaires. However, there is a major difference compared to the questionnaires concerning the career. In relating what they have done since graduating in the FD program, some people notice that there have been effects, even if they are small. Such situations were not covered by the items in the questionnaires, which explains the difference. For example, a participant now teaches in an HE institution and has to do less ongoing training than if she had not completed the course, while another participant gives adult education courses and her certificate was taken into consideration on that occasion. With regard to the effects on the work team, only one participant mentioned he had been able to revisit his final project reflections with his colleagues in the form of collective reflection under his impetus. In the other cases, participants say they were encouraged to do the training and the final paper, but that this was neither taken up at a team level, nor promoted by their superiors.

\section{RQ4. What interactions between participants and their working environment lead to what effects?}

As mentioned above (Fig. 2), the results of the descriptive analyses show that effects perceived at an individual level are more important than effects perceived at a collective level. Following these results, which raised a number of questions, we decided to undertake a further exploratory step to better understand the situation. In particular, correlations between participants' individual characteristics and the perceived collective effects (i.e. perceived effects on the work team) were tested, corresponding to following hypotheses:

- The more teaching experience participants have, the greater the perceived impact on the work team (collective effects). 
- The more participants come from a domain where such an FD program is a tradition, the greater the perceived impact on the work team (collective effects).

- The more participants grant importance to each type of entry motive, the greater the perceived impact on the work team (collective effects).

The results of the Spearman correlation between participants' individual characteristics and perceived collective effects show that there is a substantial and almost significant positive correlation between participants' teaching experience and the perceived collective effects (.324, $\mathrm{p}=.057)$. It might be called a trend. Given the size of our sample $(\mathrm{N}=40)$, a higher tolerance threshold applies to the size of the effect. Based on this result, it would appear that more experienced participants have more confidence in their teaching skills to provide guidance to their colleagues and feel more able to contribute to discussions about teaching within their team. It can also be said that their contributions are more valued and considered credible by colleagues and superiors.

Correlations between other participants' individual characteristics (tradition of taking part in the training in their field of work and entry motives) and the perceived collective effects were non-significant.

We then calculated partial correlations to try to show the importance of the perception of the working environment as a mediating variable, as postulated in the theoretical model (Fig. 1 and Table 1). Results show that if we control the "perception of the working environment" variable, the correlation between participants' individual characteristics and their perception of the collective effects decreases each time. Thus, it appears that perceived collective effects depend more on participants' perceptions of their working environment than on their individual characteristics. This variable thus plays a mediating role. 
Table 2. Partial correlations when controlling the "perception of the working environment" variable

\begin{tabular}{|l|l|}
\hline & Perceived collective effects \\
\hline Teaching experience & $\mathrm{r}=.162, \mathrm{p}=.359$ \\
\hline Tradition of taking part in the training in their & $\mathrm{r}=.199, \mathrm{p}=.282$ \\
\hline Socio-affective and identity motives & $\mathrm{r}=.095, \mathrm{p}=.592$ \\
\hline Epistemic and professional motives & $\mathrm{r}=.055, \mathrm{p}=.756$ \\
\hline Vocational and economic motives & $\mathrm{r}=-.070, \mathrm{p}=.693$ \\
\hline
\end{tabular}

To understand the relationship of the perception of the working environment with the other variables taken into account, we then calculated Spearman correlations between these different variables.

The results show that there is a substantial and significant positive correlation $(.350, p=.05)$ between the perception of the working environment and the epistemic and professional motives for undertaking training. There is also a very substantial and significant positive correlation $(.510, \mathrm{p}=.01)$ between the perception of the working environment and the vocational and economic motives. We can therefore say that there is a link between the perception of the working environment and the motives, either to build knowledge and develop professionally, or to promote one's career.

There is also a very substantial and significant positive correlation $(.527, \mathrm{p}=.01)$ between the perception of the working environment and perceived effects on the practices of the work team. Finally, it can be said that, for participants in the training, the perception of the working environment plays a very important role in the perception of the effects on the practices of the work team. 
Correlations between other participant's individual characteristics (teaching experience, tradition of taking part in the training in their field of work, and socio-affective and identity motives) and the perception of working environment were non-significant.

\section{RQ5. To what extent do the effects perceived by participants correspond to those expected of a SoTL approach?}

Our research shows that a learning environment such as SoTL (see RQ2), leads to substantial effects as perceived by teachers on their individual professional development (see RQ3). This result already merits interest in relation with the Tight Literature Review (2018). We have seen, however, that the effects on collective practices are weak. Finally, the institutional effects and those on students' learning have not been investigated here.

\section{Discussion of the results}

The high score at an individual level confirms the results of the HY-SUP research (Deschryver \& Charlier, 2014) combining type 5 environments with high perceived effects on learning as well as the impacts of FD programs adopting a SoTL approach on perceived individual professional development (Tight, 2018).

With reference to our theoretical framework, three characteristics of our FD program learning design can help understand differences in perceived effects at an individual and collective level. The intended learning outcomes do not explicitly mention impact on the collective practices; the evaluation criteria of the final project do not integrate "sharing/dissemination of expertise and best practices" (Larsson et al., 2015); and the FD program is not aligned with other indicators at an institutional level: i.e. policy "recognising and rewarding teaching through career progression, grants, etc." and culture "TPPs delivered within a culture of supporting learning communities" (Chalmers \& Gardiner, 2015, p. 88). These apparently simple interpretations are only possible thanks to a rigorous description of the FD program's 
learning design. However, the demonstration of the important role played by participants' perception of their working environments shows that these explanations are not enough. It is also necessary to take into account these perceptions, which are themselves linked to the entry motives of the participants. Previous research in HE has clearly demonstrated the effect of such mediating variables linked to student perception of their learning environments. See, for example, the concepts of approaches to learning (Biggs, 2003) and study orchestration (Meyer, 1991). "For the same environment, the HY-SUP project also showed the diversity of student perceptions, as well as a relation between these perceptions, approaches to learning and perceived effects on learning" (Charlier, Cosnefroy, Jézégou, \& Lameul, 2015, p. 391). Concerning the characteristics of the working environment, it would be necessary to describe them as we did for the learning environment.

\section{Conclusions and perspectives}

As Tight (2018) recalled about SoTL in his literature review, too little empirical research has been carried out to evaluate the training or support mechanisms for the professional development of higher education teachers. In this contribution, we have proposed a theoretical framework for the evaluation of FD programs and illustrated a concrete implementation with a case. The rigorous description of the FD program learning design with the support of shared descriptors, the fact of taking into account and describing participating individuals, the consideration of mediating variables describing the interaction between participants and the environment, as well as the description of the perceived effects not only allow the identification of the effects of these environments in a precise and rigorous way, but also the exploration of the variables enables a better understanding of these effects. Finally, as the framework and tools proposed can be adapted and applied to multiple contexts it should be possible in the future to make comparisons between environments and build a solid body of knowledge in the field. 
A certain number of limitations remain to be tackled to further improve this research.

As far as the descriptive part is concerned, the framework used is not yet fully validated and complete. Our characterization of the SoTL approach was made on the basis of the literature. It would be necessary, as was done by the HY-SUP research for hybrid learning environments, to carry out a large-scale survey to highlight types of FD learning designs. In addition, it would be necessary to describe universities' support to a SoTL approach and its alignment with the FD programs. The framework of Chalmers and Gardiner (2015) as well as the case study of Mårtensson et al. (2011) will be of great help.

With regard to the evaluation component, the main flaw is that it is exclusively based on participants' learning experience and thus on perceived effects. If we stick to perceived effects, we could add the perception of the effects by students, by colleagues and, more broadly, by the institution. Of course, the perception of the effects is not sufficient and objective criteria need to be sought, as suggested by Chalmers and Gardiner (2015). 


\section{References}

Bamber, V., \& Stefani, L. (2016). Taking up the challenge of evidencing value in educational development: from theory to practice. International Journal for Academic Development, 21(3), 242-254.

Bélanger, C. (2010). Une perspective SoTL au développement professionnel des enseignants au supérieur: Qu'est-ce que cela signifie pour le conseil pédagogique ? [A SoTL perspective on the professional development of higher education teachers: What does this mean for pedagogical advice?]. The Canadian Journal for the Scholarship of Teaching and Learning, 1(2), Article 6.

Biggs, J. (2003). Teaching for Quality Learning at University. Buckingham: The Society for Research into Higher Education and Open University Press.

Boud, D., \& Prosser, M. (2002). Appraising new technologies for learning: A framework for development. Educational Media International, 39(3-4), 237-245.

Boyer, E. L. (1990). Scholarship Reconsidered Priorities of the Professoriate. San Francisco: Jossey-Bass.

Brew, A. (2011). Higher Education Research and the Scholarship of Teaching and Learning: The Pursuit of Excellence. The Canadian Journal for the Scholarship of Teaching and Learning, 5(2), Article 3.

Chalmers, D., \& Gardiner, D. (2015). An evaluation framework for identifying the effectiveness and impact of academic teacher development programmes. Studies in Educational Evaluation, 46, 81-91.

Charlier, B., Deschryver, N., \& Peraya, D. (2006). Apprendre en présence et à distance. Distances et savoirs, 4(4), 469-496.

Charlier, B., Cosnefroy, L., Jézégou, A., \& Lameul, G. (2015). Understanding Quality of Learning in Digital Learning Environments: State of the Art and Research Needed. In A. Curaj, L. Matei, R. Pricopie, J. Salmi, \& P. Scott (Eds.), The European Higher Education Area (pp. 381-398). Cham: Springer.

Chick, N. (2015). Scholarship of Teaching and Learning: A Guide from the Vanderbilt University Center for Teaching. Retrieved from https://my.vanderbilt.edu/sotl/

Daele, A., Biémar, S., Malengrez, D., \& Oger, L. (2014). Le "Scholarship of Teaching and Learning” (SoTL). Proposition d'un cadre pour l'accompagnement des enseignants par les conseillers pédagogiques. [The "Scholarship of Teaching and Learning" 
(SoTL). Proposition of a framework for the accompaniment of teachers by faculty developers. ] Working file transmitted by the authors.

Deschryver, N., \& Charlier, B. (2014). Les dispositifs hybrides dans l'enseignement supérieur: questions théoriques, méthodologiques et pratiques. Education et formation. Entwistle, N. (2018). Student Learning and Academic Understanding: A Research Perspective with Implications for Teaching. London: Academic Press.

Fernagu-Oudet, S. (2012). Favoriser un environnement "capacitant" dans les organisations. [Fostering an "enabling" environment in organizations]. In E. Bourgeois, \& M. Durand (Eds.), Apprendre au travail (pp. 201-213). Paris: PUF.

Huet, I. (2012). Academic development as a strategy to enhance teaching quality in researchintensive universities: the Portuguese context. Higher Education Research Network Journal, 5 EFAD Special Edition, 9-18.

Johnson, R. B., \& Onwuegbuzie, A. J. (2004). Mixed methods research: A research paradigm whose time has come. Educational researcher, 33(7), 14-26.

Jones, A., Lygo-Baker, S., Markless, S., Rienties, B., \& Di Napoli, R. (2017). Conceptualizing impact in academic development: finding a way through. Higher Education Research \& Development, 36(1), 116-128.

Kolomitro, K., \& Anstey, L. M. (2017). A survey on evaluation practices in teaching and learning centres. International Journal for Academic Development, 22(3), 186-198.

Larsson, M., Anderberg, E., \& Olsson, T. (2015). Researching the transformation in the Scholarship of Teaching and Learning through teaching portfolios and conference papers. In S. Booth, \& L. Woollacott (Eds.), The Scholarship of Teaching and Learning in Higher Education: On its constitution and transformative potential (pp. 113-136). Sun Media Stellenbosch.

Mårtensson, K., Roxå, T., \& Olsson, T. (2011). Developing a quality culture through the Scholarship of Teaching and Learning. Higher Education Research \& Development, 30(1), 51-62.

Meyer, J.H.F. (1991). Study orchestration: the manifestation, interpretation and consequences of contextualised approaches to studying. Higher Education, 2(3), 297-316.

Phuong, T. T., Cole, S. C., \& Zarestky, J. (2018). A systematic literature review of faculty development for teacher educators.Higher Education Research \& Development, 37(2), 373-389. 
Rege-Colet, N., McAlpine, L., Fanghanel, J., \& Weston, C. (2011). Le concept de Scholarship of Teaching and Learning. La recherche sur l'enseignement supérieur et la formalisation des pratiques enseignantes. [The concept of Scholarship of Teaching and Learning. Research on higher education and the formalization of teaching practices]. Recherche et Formation, 67, 91-104.

Reigeluth, C. M., \& Carr-Chellman, A. A. (Eds.) (2009). Instructional-design theories and models: Building a common knowledge base (vol. III). New York: Routledge.

Tashakkori, A., \& Teddlie, C. (Eds.) (2010). Sage handbook of mixed methods in social \& behavioral research. Los Angeles: SAGE Publications.

Tight, M. (2018). Tracking the Scholarship of Teaching and Learning. Policy Reviews in Higher Education, 2(1), 61-78.

Webb, A. S. (2015). Threshold concepts in the scholarship of teaching and learning: A phenomenological study of educational leaders in a Canadian research-intensive university (Doctoral thesis). University of British Columbia, Vancouver, Canada. Retrieved from https://open.library.ubc.ca/cIRcle/collections/ubctheses/24/items/1.0167152 